\title{
Identification of volatile active components in Acori Tatarinowii Rhizome essential oil from different regions in China by $\mathrm{C} 6$ glioma cells
}

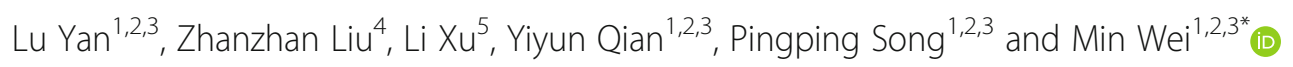

\begin{abstract}
Background: Acori Tatarinowii Rhizome (ATR) is a well-recognized Chinese herbal medicine prescribed to treat neurological disorders. The essential oil (ATEO) is considered as the active fraction of ATR and the content of ATEO is used as the only indicator for ATR content determination. The quality of ATEO varies widely due to region difference; however, little is known about how to study ATEO quality chemically and biologically in response to region difference. Thus, it is of great importance to identify volatile active components in ATEO to conduct quality study. In this study, we analyzed ATEO from different regions in China using chemical component analysis combined with biological activity evaluation.
\end{abstract}

Methods: GC-MS was used to obtain different volatile component profiles of ATEO and significantly changed volatile components were screened out. The neuroprotective activities of ATEO, including anti-oxidation, antiinflammation and neurotrophic functions, were revealed in C6 glioma cells. The correlation study between the bioactivities and the components was performed.

Results: 57 volatile components, including terpenoids, phenylpropanoids, aromatic compounds, and other aliphatic compounds, were identified. 8 volatile components ( $\beta$-asarone, cis-methyl isoeugenol, $\gamma$-asarone, methyleugenol, calarene, longifolene, $\beta$-caryophyllene and caryophyllene oxide) from ATEO were significantly changed due to region difference and 2 of them ( $\beta$-asarone and $\gamma$-asarone) showed strong correlation with neuroprotective activities.

Conclusions: Our results reveal that ATEO from different regions in China show great changes in chemical composition and biological activity. Moreover, phenylpropanoids ( $\beta$-asarone and $\gamma$-asarone) present strong correlation with the bioactivities, which are considered as volatile active components in ATEO. The findings will be useful for the development of quality study of ATEO.

Keywords: Acori Tatarinowii Rhizome, Essential oil, Region difference, Volatile active component, Neuroprotective

\footnotetext{
* Correspondence: weimin@cnbg.net

${ }^{1}$ Institute of Botany, Jiangsu Province and Chinese Academy of Sciences, Nanjing 210014, China

${ }^{2}$ Jiangsu Key Laboratory for the Research and Utilization of Plant Resources, Nanjing 210014, China

Full list of author information is available at the end of the article
}

(c) The Author(s). 2020 Open Access This article is licensed under a Creative Commons Attribution 4.0 International License, which permits use, sharing, adaptation, distribution and reproduction in any medium or format, as long as you give appropriate credit to the original author(s) and the source, provide a link to the Creative Commons licence, and indicate if changes were made. The images or other third party material in this article are included in the article's Creative Commons licence, unless indicated otherwise in a credit line to the material. If material is not included in the article's Creative Commons licence and your intended use is not permitted by statutory regulation or exceeds the permitted use, you will need to obtain permission directly from the copyright holder. To view a copy of this licence, visit http://creativecommons.org/licenses/by/4.0/ The Creative Commons Public Domain Dedication waiver (http://creativecommons.org/publicdomain/zero/1.0/) applies to the data made available in this article, unless otherwise stated in a credit line to the data. 


\section{Background}

The rigorous implementation of Drug Administration Law (DAL) and Good Agricultural Practices (GAP) plays a key role in promoting the quality study of Chinese herbal medicine and ensuring the safety, efficacy, and quality consistency of final drugs [1]. Chinese herbal raw materials from diverse regions undergo standard operating procedures during planting, processing and pharmaceutical production. Thus, the region difference is likely to be one of the major reasons for the heterogeneous quality of final drugs as the difference directly affects chemical composition and biological activity of Chinese herbal medicine [2,3]. However, current quality study approaches for Chinese herbal medicine are not able to perform an overall evaluation on region difference [4]. Therefore, to achieve an improvement in quality study, the impact of region should be under serious consideration. Appropriate research is required to deepen the knowledge of quality study with region difference; this knowledge will enhance the regulation and quality of Chinese herbal medicine [5, 6].

Acori Tatarinowii Rhizoma (ATR, the dried rhizome of Acorus tatarinowii Schott) is one of the most important Chinese herbal medicines, which has been used in treating neurological disorders for thousands of years [7]. Extracts of ATR enhance neurogenesis and neuroprotection in both animal and clinical studies [8-10]. According to Chinese Pharmacopoeia, the major active fraction of ATR is the essential oil, and the content of ATR essential oil (ATEO) is considered as the only indicator for ATR content determination [11]. ATEO is reported to contain different groups of chemical constituents including terpenoids, phenylpropanoids and aromatic compounds, which have neuroprotective activities as anti-oxidation, anti-inflammation and neurotrophic function [12-15].

Our study on resources of Chinese herbal medicine has found that Acorus tatarinowii Schott shows advantage of wide growth adaptability which is mainly distributed to the south of the Yellow River in China. Six major regions in China include mountain areas in Anhui $(\mathrm{AH})$, Hubei $(\mathrm{HB})$ and Yunnan $(\mathrm{YN})$ provinces, valley area in Hunan (HN) province, hilly area in Jiangxi (JX) province and hilly basin area in Zhejiang (ZJ) province. These regions present great differences in geographical environment, and it seems likely that the diversity leads to various problems, including an uneven quality of ATEO and its products [16]. However, there are few reports to compare ATEO quality in these regions, and greater efforts are needed to study ATEO quality with region diversity.

Region difference causes variation in chemical composition and consequently affects bioactivity of herbal medicine, and determining how to chemically and biologically analyze samples from different regions is the key to study the quality of ATEO $[17,18]$. First, the variation in chemical composition may reflect the changes in type and amount of components. However, few studies clearly illustrate the variation of chemical composition in ATEO from different regions. Second, changes in type and amount of components in response to region difference would lead to changes in biological activity of ATEO. The beneficial effects of ATEO may not be attributed to one single substance, but are believed to involve a series of active components found in ATEO [19]. Study on biological activity analyzes the effects of all the active components in ATEO and the action of each component. Therefore, finding volatile active components in ATEO from different regions in China using chemical component analysis combined with biological activity evaluation is applied to explore quality study with region difference.

In the study, we aimed to identify volatile active components in ATEO from six major regions in China. GCMS was used to obtain different volatile component profiles of ATEO and significantly changed volatile components were identified by one-way ANOVA and partial least-squares discriminant analysis (PLS-DA). Astrocytes are the major glial cells in the central nervous system and play a crucial role in neuroprotection, including anti-oxidation, anti-inflammation and neurotrophic function [20-22]. Thus, C6 glioma cells, an astrocytelike cell line, were selected as the cell model to investigate the neuroprotective activities of ATEO samples [23]. We then analyzed the correlation between the bioactivities and the components to figure out volatile active components in ATEO. Our results reveal that ATEO samples from six major regions in China show great changes in chemical composition and biological activity. Moreover, phenylpropanoids ( $\beta$-asarone and $\gamma$ asarone) present strong correlation with the bioactivities, which are considered as volatile active components in ATEO. The findings will be useful for the development of quality study of ATEO, which, in turn, enhance the medicinal benefits and find good resources of ATR.

\section{Methods \\ Reagents and chemicals}

n-Alkanes were purchased from Shanghai ANPEL Scientific Instrument (Shanghai, China). Ultra-pure water was prepared from a Milli-Q purification system (Millipore, Molsheim, France). N-hexane and other reagents were from Sigma-Aldrich (St. Louis, MO).

\section{Preparation of ATEO}

ATR samples from six major regions were obtained from Bozhou Market in Anhui China, and were morphologically authenticated by Dr. Min Wei, Institute of Botany, 
Jiangsu Province and Chinese Academy of Sciences, Nanjing. The sampling details are shown in Table 1 and Additional file 1 . The corresponding voucher specimens were deposited in Research Center of Medicinal Plants of Institute of Botany, Jiangsu Province and Chinese Academy of Science. The plant materials were tested for quality according to the requirements of Chinese Pharmacopeia (2015 Edition). In preparing the essential oil, $100 \mathrm{~g}$ of the plant materials were minced and soaked in $800 \mathrm{~mL}$ of water for $1 \mathrm{~h}$. The mixture was submitted to hydro-distillation in a volatile oil extractor for $8 \mathrm{~h}[11$, 13]. The resultant ATEO was collected, dried over anhydrous sodium sulfate and stored at $-20^{\circ} \mathrm{C}$.

\section{GC-MS analysis}

GC-MS analysis was performed on a TRACE 1300/ISQLT (Thermo Fisher Scientific, Waltham, MA). The chromatographic separation was conducted on an Agilent J\&W DB-5 capillary column $(30 \mathrm{~m} \times 0.25 \mathrm{~mm}, 0.25 \mu \mathrm{m}$, Agilent Technologies, Santa Clara, CA) using the following temperature profile: $60^{\circ} \mathrm{C}$ for $4 \mathrm{~min}, 60-150^{\circ} \mathrm{C}$ at $12{ }^{\circ} \mathrm{C} / \mathrm{min}, 150-170{ }^{\circ} \mathrm{C}$ at $1{ }^{\circ} \mathrm{C} / \mathrm{min}, 170-250^{\circ} \mathrm{C}$ at $30^{\circ} \mathrm{C} /$ min, and held for $3 \mathrm{~min}$; inlet temperature, $250^{\circ} \mathrm{C}$; transfer-line temperature, $250^{\circ} \mathrm{C}$; split ratio, $1: 33.3$. The mass spectrometer was operated in the electron impact (EI) mode with energy of $70 \mathrm{eV}$, and data were collected at a rate of $5 \mathrm{scan} / \mathrm{s}$ over a range of $\mathrm{m} / \mathrm{z} 33-450$. The ion source was kept at $250^{\circ} \mathrm{C}$ [24]. For qualitative analysis of ATEO, the individual peak was identified by comparing their mass spectra with the mass spectral library (NIST14), with MS spectra and MS fragmentation pattern published in the literature and with relative retention index by injecting a mixture of $\mathrm{n}$-alkanes. For relative quantification of ATEO, the individual peak was integrated manually and their relative contents were calculated by peak area normalization method.

\section{Cell culture}

C6 glioma cells (ATCC ${ }^{\circ}$ CCL-107) were obtained from American Type Culture Collection (ATCC, Manassas, VA), and were cultured in Dulbecco's modified Eagle's medium (DMEM), supplemented with 10\% fetal bovine serum (FBS), 100 units $/ \mathrm{mL}$ penicillin and $100 \mu \mathrm{g} / \mathrm{mL}$

Table 1 Details of ATEO samples from six major regions used in this study

\begin{tabular}{ll}
\hline ATEO samples & Locality \\
\hline ATEO-AH & Yuexi Country, Anqing, Anhui (AH) \\
ATEO-HB & Yidu Country, Yichang, Hubei (HB) \\
ATEO-HN & Yuanling Country, Huaihua, Hunan (HN) \\
ATEO-JX & Taihe Country, Ji'an, Jiangxi (JX) \\
ATEO-YN & Tengchong Country, Baoshan, Yunnan (YN) \\
ATEO-ZJ & Pan'an Country, Jinhua, Zhejiang (ZJ) \\
\hline
\end{tabular}

streptomycin in a humidified $\mathrm{CO}_{2}(5 \%)$ incubator at $37^{\circ} \mathrm{C}$. Culture medium was changed every other day. All culture reagents were purchased from Thermo Fisher Scientific.

\section{Drug treatment}

In brief, cultured $\mathrm{C} 6$ cells were treated with different concentrations of ATEO $(1.5,5,15 \mu \mathrm{g} / \mathrm{mL})$ for 24 or 48 $\mathrm{h}$. The culture medium was replaced $3 \mathrm{~h}$ prior to drug treatment. In luciferase assay, the cells were pre-treated with ATEO $(1.5,5,15 \mu \mathrm{g} / \mathrm{mL})$ for $24 \mathrm{~h}$. Forskolin (FSK, Sigma, St. Louis, MO, $10 \mu \mathrm{M}$ ) and ZLN005 (MCE, Monmouth Junction, NJ, $2 \mu \mathrm{M}$ ) were used as positive control, respectively. In mRNA assay, cultured C6 cells were treated with ATEO $(15 \mu \mathrm{g} / \mathrm{mL})$ for $48 \mathrm{~h}$ with or without tumor necrosis factor- $\alpha$ (TNF- $\alpha$, Sigma, St. Louis, MO, $10 \mathrm{ng} / \mathrm{mL}$ ) and interferon- $\gamma$ (IFN- $\gamma$, Sigma, St. Louis, $\mathrm{MO}, 10 \mathrm{ng} / \mathrm{mL}$ ) pretreatment for another $24 \mathrm{~h}$ [25].

\section{Luciferase assay}

Two promoter constructs were purchased from FulenGen (Guangzhou, China), namely pCRE-Luc and pPGC$1 \alpha$-Luc, carrying cAMP response element (CRE) and peroxisome proliferator-activated receptor- $\gamma$ coactivator$1 \alpha(\mathrm{PGC}-1 \alpha)$ promoter sequences, respectively. Cultured C6 cells were seeded in 12-well plates at a density of $1 \times$ $10^{5}$ per well and stayed overnight. Then the cells were transiently transfected with pCRE-Luc and pPGC-1 $\alpha$ Luc by lipofectamine 3000 reagent (Thermo Fisher Scientific), respectively [26]. After drug treatment, the cells were harvested and luciferase activity was measured using the Luc-Pair ${ }^{\text {rx }}$ Duo-Luciferase HS Assay kit (GeneCopoeia, Rockville, MD). Firefly luciferase activity was normalized to Renilla luciferase activity.

\section{Real-time quantitative PCR}

Total RNA was isolated from cell cultures by RNA Isolation Kit (Vazyme, Nanjing, China) according to the manufacturer's instructions. The concentrations of RNAs were detected by UV absorbance at $260 \mathrm{~nm}$. cDNA was reverse transcribed from $1 \mu \mathrm{g}$ samples of total RNA using RT SuperMix for qPCR (Vazyme), according to the protocol provided by the manufacturer. Real-time PCR was performed using SYBR Green Master Mix (Vazyme). The SYBR green signal was detected by qTOWER 2.0 (Analytic Jena AG, Germany). Primers used were: 18S-S: TGT GAT GCC CTT AGA TGT CC; 18S-AS: GAT AGT CAA GTT CGA CCG TC; NGF-S: CAC TCT GAG GTG CAT AGC GTA ATG TC; NGFAS: CTG TGA GTC CTG TTG AAG GAG ATT GTA C; BDNF-S: GAG CTG AGC GTG TGT GAC AGT ATT AG; BDNF-AS: ATT GGG TAG TTC GGC ATT GCG AGT TC; GDNF-S: GCG CTG ACC AGT GAC TCC AAT ATG; GDNF-AS: CGC TTC ACA GGA 
ACC GCT ACA ATA TC; GPx1-S: GGA CTA CAC CGA AAT GAA TGA TCT G; GPx1-AS: GAA GGT AAA GAG CGG GTG AGC; SOD2-S: GCC AAG GGA GAT GTT ACA ACT CAG; SOD2-AS: GCA GTG GGT CCT GAT TAG AGC AG; UCP2-S: ACG ACC TCC CTT GCC ACT TCA C; UCP2-AS: CAA GCG GAG GAA GGA AGG CAT G; IL-1 $\beta$-S: GAT GAA AGA CGG CAC ACC CAC C; IL-1 $\beta-A S:$ GAG AGG TGC TGA TGT ACC AGT TG; IL-6-S: CTG GAG TTC CGT TTC TAC CTG GAG; IL-6-AS: GAT GGT CTT GGT CCT TAG CCA CTC; TNF- $\alpha-S$ : GAC CCT CAC ACT CAG ATC ATC TTC; TNF- $\alpha$-AS: GTG GGT GAG GAG CAC ATA GTC G.

\section{Statistical analysis}

The resulting GC-MS datasets were analyzed using an online tool, MetaboAnalyst 4.0 (www.metaboanalyst.ca) [27]. Data were normalized by sum and auto scaling. One-way ANOVA, clustering analysis and PLS-DA were used for classification analysis. In PLS-DA, the quality of the fitting model can be explained by the appropriate $R^{2}$ and $Q^{2}$ values. $R^{2}$ is defined as the total amount of variation explained by the model and $\mathrm{Q}^{2}$ is the indicated predictability of the model under cross validation. The PLS-DA was validated by a permutation tests (1000 random iterations) [28]. A multi-criteria assessment (MCA), including variable importance in projection (VIP) values and $p$ values, were used to screen and select significantly changed volatile components. The MCA was performed using the followed criteria: 1 . VIP $>1$ and 2. $p<0.05$ [29]. The correlation analysis between activity data and relative contents was performed using RStudio 1.1.463 for R statistical computing (www.rstudio.com/).

All data were analyzed using one-way ANOVA or Students t-test method. Differences with values of $p<0.05$ were considered significant.

\section{Results}

Different volatile component profiles of ATEO from six major regions in China

To investigate the variation in chemical composition present in ATEO from six major regions in China, GCMS analysis was used to detect the holistic volatile component profiles of ATEO. Typical GC-MS spectra of ATEO from six regions are presented in Fig. 1; a wide range of volatile components were unambiguously identified based on mass spectral library (NIST14), MS fragmentation pattern published in the literature, and relative retention index by injecting a mixture of $n$ alkanes [30-33] (Additional file 2). 57 volatile components, including terpenoids, phenylpropanoids, aromatic compounds, and other aliphatic compounds, were identified and quantification of these components was performed by peak area normalization method, as

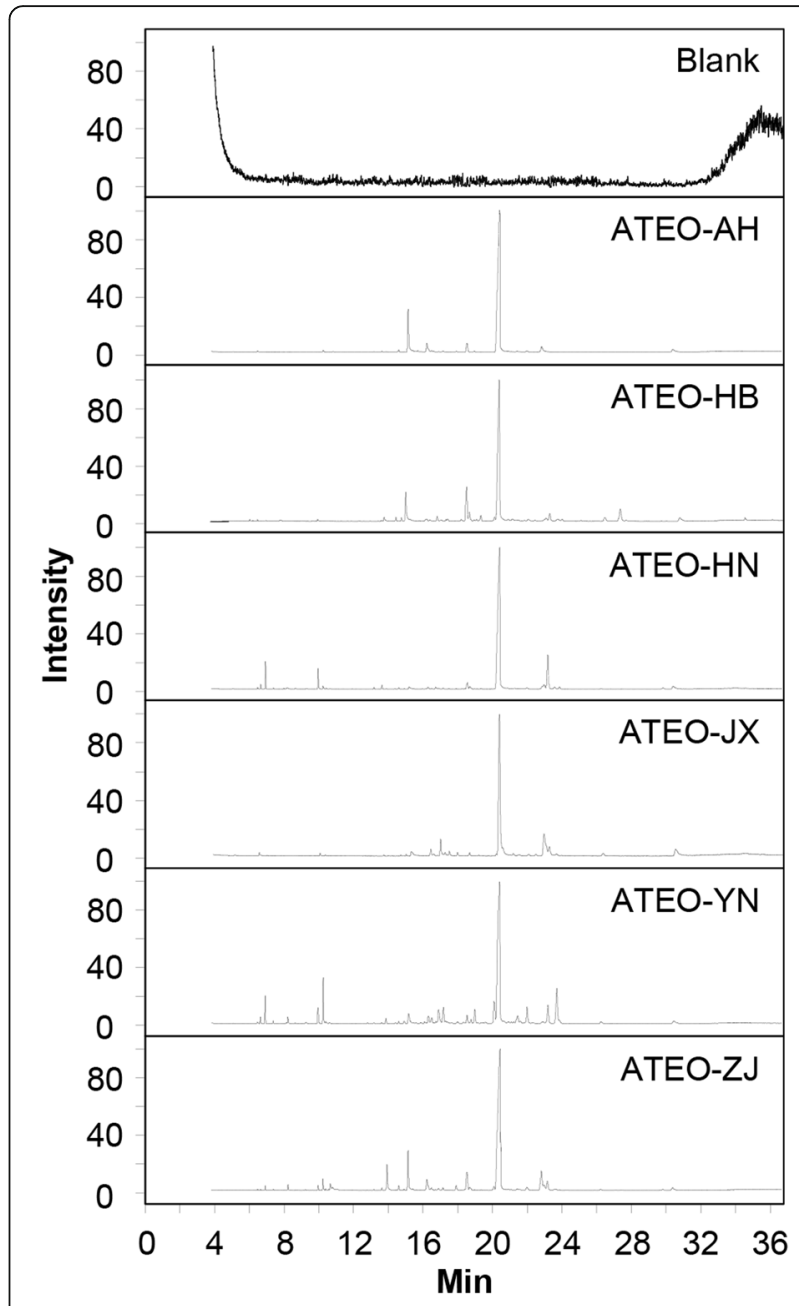

Fig. 1 Total ion chromatogram of ATEO. The chromatographic method was described in Methods. The identification of 57 compounds was made by comparing their mass spectra with the mass spectral library (NIST14), with MS spectra and MS fragmentation pattern published in the literature and with Relative Retention Index by injecting a mixture of n-alkanes. Representative chromatograms are shown, $n=6$

summarized in Table 2 . The primary volatile components, particularly terpenoids, phenylpropanoids and aromatic compounds, were confirmed. The relative contents of terpenoids, phenylpropanoids and aromatic compounds were greatly changed when ATEO from the six major regions were compared.

\section{Significantly changed volatile component analysis in ATEO from six major regions in China}

To comprehensively analyze the information contained in ATEO from six major regions $(\mathrm{AH}, \mathrm{HB}, \mathrm{HN}, \mathrm{JX}, \mathrm{YN}$ and ZJ), one-way ANOVA, clustering analysis and PLSDA were applied to classify these data using an online tool, MetaboAnalyst 4.0 (www.metaboanalyst.ca). In one-way ANOVA, 24 components were differentially 
Table 2 Normalized relative content of components from GC/MS of ATEO from six major regions in China

\begin{tabular}{|c|c|c|c|c|c|c|}
\hline \multirow[t]{2}{*}{ Component } & \multicolumn{6}{|c|}{ Normalized relative content (\%) } \\
\hline & ATEO-AH & ATEO-HB & ATEO-HN & ATEO-JX & ATEO-YN & ATEO-ZJ \\
\hline \multicolumn{7}{|l|}{ Terpenoids } \\
\hline a-Pinene & - & - & $0.82 \pm 0.10$ & - & $0.65 \pm 0.04$ & $0.14 \pm 0.06$ \\
\hline Camphene & - & $0.21 \pm 0.01$ & $4.95 \pm 1.10$ & $0.04 \pm 0.02$ & $2.63 \pm 0.36$ & $0.70 \pm 0.34$ \\
\hline$\beta$-Pinene & - & - & $0.23 \pm 0.04$ & - & $0.28 \pm 0.05$ & $0.17 \pm 0.07$ \\
\hline a-Terpinene & - & - & $0.14 \pm 0.02$ & - & $0.04 \pm 0.01$ & - \\
\hline d-Limonene & - & - & $0.25 \pm 0.07$ & - & - & - \\
\hline Eucalyptol & - & - & $0.16 \pm 0.00$ & - & $0.70 \pm 0.18$ & $0.77 \pm 0.19$ \\
\hline Y-Terpinene & - & - & $0.17 \pm 0.03$ & - & $0.07 \pm 0.02$ & $0.06 \pm 0.01$ \\
\hline Linalool & - & - & $0.08 \pm 0.02$ & - & $0.16 \pm 0.08$ & $0.16 \pm 0.07$ \\
\hline 2-Bornanone & $0.21 \pm 0.12$ & $0.05 \pm 0.01$ & $3.45 \pm 0.33$ & $0.87 \pm 0.24$ & $1.25 \pm 0.36$ & $0.62 \pm 0.07$ \\
\hline endo-Borneol & $0.44 \pm 0.12$ & $0.30 \pm 0.03$ & $0.61 \pm 0.07$ & $0.21 \pm 0.05$ & $4.02 \pm 1.04$ & $1.42 \pm 0.15$ \\
\hline Terpinen-4-ol & - & - & $0.19 \pm 0.03$ & $0.06 \pm 0.01$ & $0.19 \pm 0.03$ & $0.20 \pm 0.04$ \\
\hline a-Terpineol & $0.07 \pm 0.02$ & - & $0.06 \pm 0.01$ & $0.06 \pm 0.01$ & $0.10 \pm 0.04$ & - \\
\hline$\delta$-Elemene & - & - & - & - & - & $0.11 \pm 0.05$ \\
\hline a-Longipinene & $0.10 \pm 0.04$ & - & $0.39 \pm 0.07$ & $0.04 \pm 0.00$ & $0.10 \pm 0.03$ & $0.13 \pm 0.01$ \\
\hline Longicyclene & $0.21 \pm 0.07$ & - & $0.93 \pm 0.14$ & $0.31 \pm 0.02$ & $0.18 \pm 0.07$ & $0.40 \pm 0.02$ \\
\hline a-Patchoulene & - & $0.18 \pm 0.01$ & - & - & - & - \\
\hline$\beta$-Elemene & $0.15 \pm 0.04$ & - & $0.16 \pm 0.05$ & $0.14 \pm 0.03$ & $0.82 \pm 0.28$ & - \\
\hline Longifolene & $0.43 \pm 0.29$ & - & $0.11 \pm 0.01$ & $0.21 \pm 0.19$ & $0.21 \pm 0.08$ & $0.06 \pm 0.01$ \\
\hline$\beta$-Caryophyllene & $0.78 \pm 0.23$ & $0.81 \pm 0.04$ & $0.37 \pm 0.04$ & $0.30 \pm 0.05$ & $0.32 \pm 0.01$ & $0.92 \pm 0.30$ \\
\hline Cedr-8(15)-ene & - & $0.14 \pm 0.02$ & $0.15 \pm 0.07$ & - & $0.24 \pm 0.19$ & $0.14 \pm 0.07$ \\
\hline Calarene & $0.20 \pm 0.12$ & $0.79 \pm 0.10$ & $0.11 \pm 0.02$ & $0.48 \pm 0.11$ & $0.34 \pm 0.02$ & $0.21 \pm 0.02$ \\
\hline a-Caryophyllene & $0.12 \pm 0.02$ & - & - & - & - & $0.17 \pm 0.07$ \\
\hline a-Acoradiene & $0.34 \pm 0.07$ & - & - & - & - & - \\
\hline Y-Muurolene & - & - & - & - & $0.30 \pm 0.08$ & $0.09 \pm 0.04$ \\
\hline Germacrene D & - & - & - & - & $0.31 \pm 0.04$ & - \\
\hline Shyobunone & $0.43 \pm 0.10$ & $1.97 \pm 0.21$ & $0.20 \pm 0.01$ & $7.96 \pm 1.63$ & $2.41 \pm 0.75$ & $0.38 \pm 0.12$ \\
\hline$\delta$-Cadinene & $0.34 \pm 0.17$ & $0.27 \pm 0.06$ & $0.24 \pm 0.02$ & $1.17 \pm 0.56$ & $3.24 \pm 0.57$ & $0.55 \pm 0.12$ \\
\hline Isoshyobunone & - & $1.35 \pm 0.13$ & - & $1.91 \pm 0.88$ & $4.43 \pm 0.82$ & $0.08 \pm 0.03$ \\
\hline a-Panasinsen & - & $0.61 \pm 0.08$ & $0.21 \pm 0.02$ & - & - & $0.08 \pm 0.00$ \\
\hline a-Calacorene & - & - & - & $1.79 \pm 0.95$ & - & - \\
\hline Elemol & - & - & - & - & $0.51 \pm 0.14$ & - \\
\hline Eremophila ketone & - & $1.98 \pm 0.23$ & $0.72 \pm 0.18$ & - & - & $0.72 \pm 0.16$ \\
\hline Germacrene D-4-ol & $0.25 \pm 0.05$ & $0.24 \pm 0.05$ & - & - & $3.25 \pm 0.81$ & $0.10 \pm 0.02$ \\
\hline Spathulenol & - & $0.39 \pm 0.02$ & - & $0.28 \pm 0.10$ & - & $0.09 \pm 0.01$ \\
\hline Caryophyllene oxide & $0.05 \pm 0.01$ & $1.66 \pm 0.14$ & $0.21 \pm 0.02$ & $0.14 \pm 0.03$ & - & $0.12 \pm 0.01$ \\
\hline Viridiflorol & $0.05 \pm 0.01$ & - & - & - & $0.33 \pm 0.12$ & $0.11 \pm 0.02$ \\
\hline $\begin{array}{l}\text { Dehydroxy- } \\
\text { isocalamendiol }\end{array}$ & - & $0.64 \pm 0.06$ & - & $0.80 \pm 0.13$ & $0.14 \pm 0.01$ & $0.05 \pm 0.01$ \\
\hline tau-Cadinol & $0.36 \pm 0.16$ & $0.38 \pm 0.19$ & - & $0.60 \pm 0.10$ & $2.64 \pm 1.08$ & $0.47 \pm 0.18$ \\
\hline a-Cadinol & $0.36 \pm 0.18$ & $0.48 \pm 0.18$ & $0.42 \pm 0.19$ & $0.82 \pm 0.25$ & $4.81 \pm 1.23$ & $0.90 \pm 0.21$ \\
\hline Spiro[4.5]dec-6-en-8-one, 1,7-dimethyl-4- (1-methylethyl)- & $0.09 \pm 0.03$ & $1.00 \pm 0.16$ & $0.83 \pm 0.15$ & $0.88 \pm 0.18$ & - & $0.52 \pm 0.09$ \\
\hline Shyobunol & - & - & - & - & $9.24 \pm 1.64$ & - \\
\hline
\end{tabular}


Table 2 Normalized relative content of components from GC/MS of ATEO from six major regions in China (Continued)

\begin{tabular}{|c|c|c|c|c|c|c|}
\hline \multirow[t]{2}{*}{ Component } & \multicolumn{6}{|c|}{ Normalized relative content (\%) } \\
\hline & ATEO-AH & ATEO-HB & ATEO-HN & ATEO-JX & ATEO-YN & ATEO-ZJ \\
\hline Isocalamenediol & - & $1.79 \pm 0.56$ & - & $1.92 \pm 0.77$ & $0.40 \pm 0.07$ & $0.30 \pm 0.11$ \\
\hline \multicolumn{7}{|l|}{ Phenylpropanoids } \\
\hline Methyleugenol & $0.11 \pm 0.02$ & $0.81 \pm 0.08$ & - & $1.11 \pm 1.04$ & - & $4.39 \pm 0.42$ \\
\hline cis-Methyl isoeugenol & $14.85 \pm 2.08$ & $7.60 \pm 0.85$ & $0.85 \pm 0.27$ & $3.51 \pm 1.41$ & $1.56 \pm 0.40$ & $7.46 \pm 0.95$ \\
\hline $\begin{array}{l}\text { Benzene, 1,2-dimethoxy- } \\
\text { 4-(1-propenyl)- }\end{array}$ & $3.57 \pm 0.88$ & - & - & - & - & $2.46 \pm 0.31$ \\
\hline Elemicin & $0.22 \pm 0.07$ & - & $0.12 \pm 0.07$ & - & - & $0.86 \pm 0.25$ \\
\hline Y-Asarone & $2.78 \pm 0.54$ & $9.39 \pm 1.09$ & $2.18 \pm 0.76$ & $1.76 \pm 0.53$ & $1.28 \pm 0.33$ & $3.53 \pm 0.67$ \\
\hline$\beta$-Asarone & $69.97 \pm 4.24$ & $52.45 \pm 4.20$ & $61.38 \pm 4.34$ & $55.21 \pm 6.48$ & $45.88 \pm 7.90$ & $57.62 \pm 5.71$ \\
\hline a-Asarone & $2.78 \pm 1.06$ & $0.98 \pm 0.29$ & $1.53 \pm 0.22$ & $15.12 \pm 4.26$ & $0.53 \pm 0.20$ & $5.65 \pm 1.71$ \\
\hline \multicolumn{7}{|l|}{ Aromatic compounds } \\
\hline Benzene, (1-methylethyl)- & $0.14 \pm 0.03$ & $0.22 \pm 0.05$ & $0.29 \pm 0.04$ & $0.31 \pm 0.25$ & $0.16 \pm 0.02$ & $0.16 \pm 0.03$ \\
\hline o-Cymene & - & $0.16 \pm 0.04$ & $0.16 \pm 0.01$ & - & $0.06 \pm 0.02$ & - \\
\hline Estragole & $0.13 \pm 0.03$ & - & - & - & - & $1.62 \pm 0.17$ \\
\hline Aihydroagarofuran & - & - & - & - & $0.39 \pm 0.07$ & - \\
\hline Aristolone & - & $8.96 \pm 2.95$ & $14.15 \pm 2.37$ & $2.90 \pm 0.63$ & $5.31 \pm 1.04$ & $3.10 \pm 1.12$ \\
\hline $\begin{array}{l}\text { 6-Isopropenyl-4,8a-dimethyl-1,2,3,5,6,7,8,8a-octahydronaphthalene-2, } \\
\text { 3-diol }\end{array}$ & - & - & $0.60 \pm 0.20$ & - & - & $0.20 \pm 0.04$ \\
\hline \multicolumn{7}{|l|}{ Others } \\
\hline 2-Pentanone, 4-hydroxy-4-methyl- & $0.03 \pm 0.01$ & - & - & $0.10 \pm 0.04$ & - & $0.06 \pm 0.01$ \\
\hline Bornyl acetate & - & - & $0.07 \pm 0.02$ & $0.04 \pm 0.02$ & - & $0.05 \pm 0.01$ \\
\hline Total & $\begin{array}{l}97.26 \pm \\
2.19\end{array}$ & $\begin{array}{l}92.79 \pm \\
6.71\end{array}$ & $\begin{array}{l}95.22 \pm \\
3.23\end{array}$ & $\begin{array}{l}98.70 \pm \\
4.87\end{array}$ & $\begin{array}{l}94.84 \pm \\
3.38\end{array}$ & $\begin{array}{l}97.72 \pm \\
1.79\end{array}$ \\
\hline
\end{tabular}

changed when ATEO from six regions were compared $(p<0.05$; FDR $<0.05$; Table 3$)$, including 18 terpenoids, such as caryophyllene oxide, calarene, cedr-8(15)-ene, spiro[4.5]dec-6-en-8-one, 1,7-dimethyl-4-(1-methylethyl)-, isoshyobunone, isocalamenediol, shyobunol, longifolene, $\beta$-caryophyllene, terpinen-4-ol, $\alpha$-longipinene, longicyclene, 2 -bornanone, camphene, $\alpha$-cadinol, $\delta$-cadinene, $\beta$ elemene, and endo-borneol, 5 phenylpropanoids, such as methyleugenol, cis-methyl isoeugenol, $\gamma$-asarone, $\beta$ asarone, and $\alpha$-asarone and 1 aromatic compound, such as aristolone. The relative levels of components in ATEO from six regions were visualized on a heat map (Fig. 2a). The clustering analysis was made on 36 ATEO samples from different regions (Fig. 2b). The PLS-DA of the first three components $\left(R^{2} X=0.921\right.$ and $\left.Q^{2}=0.857\right)$ showed a great separation among ATEO from six regions (Fig. 2c).

Based on these findings, MCA was used to screen significantly changed volatile components based on the following criteria: VIP $>1$ in PLS-DA and $p<0.05$ in ttests. 8 volatile components from ATEO were significantly changed due to region diversity (Fig. 2d), as listed in Table 4; these significantly changed volatile components were involved in phenylpropanoids ( $\beta$-asarone, cis-methyl isoeugenol, $\gamma$-asarone and methyleugenol) and terpenoids (calarene, longifolene, $\beta$-caryophyllene and caryophyllene oxide). It is worth noting that more than fifteen-fold change in the relative contents of methyleugenol and cis-methyl isoeugenol and less than seven-fold change in the relative contents of $\beta$-asarone and $\gamma$-asarone, when samples from six regions were compared using this approach.

\section{Variation in the bioactivity of ATEO from six major regions in China}

The bioactivity of ATEO from six major regions in China was screened by C6 glioma cells. A cell viability assay was performed to determine a safe concentration range $(0-15 \mu \mathrm{g} / \mathrm{mL})$ of ATEO (the concentrations at which all extracts did not induce cell proliferation or death; Additional file 3). The inflammation response could be triggered by co-treatment with TNF- $\alpha$ and IFN- $\gamma$ in cultured C6 cells [25]. Treatment of TNF- $\alpha$ and IFN- $\gamma(10+10 \mathrm{ng} / \mathrm{mL})$ showed the maximal induction of interleukin-1 $\beta$ (IL-1 $\beta$ ), interleukin- 6 (IL-6) and TNF- $\alpha$ mRNA expression in cultured C6 cells and this concentration was selected for further study (Additional file 4). cAMP-response element binding protein (CREB) and PGC- $1 \alpha$ are master regulators of anti- 
Table $3 \mathrm{~T}$ test of 24 components differentially changed in ATEO samples according to GC-MS analysis

\begin{tabular}{|c|c|c|}
\hline Component & $p$-value & FDR \\
\hline 2-Bornanone & $1.06 \mathrm{E}-14$ & $1.42 \mathrm{E}-13$ \\
\hline Aristolone & 1.09E-14 & $1.42 \mathrm{E}-13$ \\
\hline cis-Methyl isoeugenol & $6.02 \mathrm{E}-14$ & $5.22 \mathrm{E}-13$ \\
\hline Camphene & $2.19 \mathrm{E}-12$ & $1.43 \mathrm{E}-11$ \\
\hline a-Longipinene & $7.18 \mathrm{E}-12$ & 3.39E-11 \\
\hline Longicyclene & $7.81 \mathrm{E}-12$ & $3.39 \mathrm{E}-11$ \\
\hline Terpinen-4-ol & $1.35 \mathrm{E}-11$ & $5.00 \mathrm{E}-11$ \\
\hline a-Asarone & $1.58 \mathrm{E}-10$ & $5.14 \mathrm{E}-10$ \\
\hline$\gamma$-Asarone & $2.15 \mathrm{E}-10$ & $6.20 \mathrm{E}-10$ \\
\hline $\begin{array}{l}\text { Spiro[4.5]dec-6-en-8-one, 1,7- } \\
\text { dimethyl-4-(1-methylethyl)- }\end{array}$ & $1.16 \mathrm{E}-08$ & $3.02 \mathrm{E}-08$ \\
\hline Calarene & $1.56 \mathrm{E}-07$ & $3.68 \mathrm{E}-07$ \\
\hline Shyobunone & $2.10 \mathrm{E}-07$ & 4.55E-07 \\
\hline a-Cadinol & $2.53 \mathrm{E}-07$ & 4.71E-07 \\
\hline$\beta$-Elemene & $2.54 \mathrm{E}-07$ & 4.71E-07 \\
\hline endo-Borneol & $3.55 \mathrm{E}-07$ & $6.15 \mathrm{E}-07$ \\
\hline Methyleugenol & $5.14 \mathrm{E}-07$ & $8.35 \mathrm{E}-07$ \\
\hline$\beta$-Asarone & $6.19 \mathrm{E}-07$ & 9.47E-07 \\
\hline Isocalamenediol & $1.13 \mathrm{E}-06$ & $1.63 \mathrm{E}-06$ \\
\hline Caryophyllene oxide & $2.16 \mathrm{E}-06$ & $2.95 \mathrm{E}-06$ \\
\hline$\delta$-Cadinene & 7.67E-05 & $9.98 \mathrm{E}-05$ \\
\hline Cedr-8(15)-ene & 0.0027017 & 0.003345 \\
\hline Isoshyobunone & 0.0047441 & 0.0056067 \\
\hline$\beta$-Caryophyllene & 0.0079356 & 0.0089707 \\
\hline Longifolene & 0.02099 & 0.022739 \\
\hline
\end{tabular}

inflammation, anti-oxidation and neurotrophic factor expression during neuroprotection. The up-regulation of CREB and PGC- $1 \alpha$ expression induces the expression of several anti-oxidant and anti-inflammatory proteins as well as neurotrophic factors [34-36]. Therefore, the transcriptional activities of CRE and PGC- $1 \alpha$ were selected for dosage screening of ATEO. ATEO samples induced CRE and PGC- $1 \alpha$ transcriptional activities in dose-dependent manners: the maximal induction of promoter activities was observed at $\sim 15 \mu \mathrm{g} / \mathrm{mL}$ (Fig. 3).

The bioactivities of anti-inflammation (IL-1 $\beta$, IL-6 and TNF- $\alpha$ ), anti-oxidation [glutathione peroxidase 1 (GPx1), superoxide dismutase 2 (SOD2) and uncoupling protein2 (UCP2)] and neurotrophic [nerve growth factor (NGF), brain-derived neurotrophic factor (BDNF) and glial cell-derived neurotrophic factor (GDNF)] were selected for further study. The results indicated that the ATEO samples $(15 \mu \mathrm{g} / \mathrm{mL})$ significantly inhibited inflammation by reducing the expression of pro-inflammatory cytokines (IL-1 $\beta$, IL- 6 and TNF- $\alpha$ ), and had great antioxidant and neurotrophic effects in promoting the expression of anti-oxidant proteins (GPx1, SOD2 and UCP2) and neurotrophic factors (NGF, BDNF and GDNF) (Fig. 4). Next, we performed correlation analysis between the bioactivities (IL-1 $\beta$, IL-6, TNF- $\alpha$, GPx1, SOD2, UCP2, NGF, BDNF and GDNF) and the significantly changed volatile components using RStudio 1.1.463 (www.rstudio.com/) (Fig. 5). The correlation coefficients between the bioactivities and the components were shown in Table 5. The correlation ranges $|\mathrm{r}| \geq 0.6$ and $p<0.05$ were considered as strong correlation [37]. The anti-inflammatory and neurotrophic activity of ATEO was strongly and positively correlated with the content of $\beta$-asarone. The anti-oxidant activity of ATEO was strongly and positively correlated with the content of $\gamma$-asarone. The results indicated strong correlation between the bioactivities and significantly changed volatile components ( $\beta$-asarone and $\gamma$-asarone). Therefore, these significantly changed volatile components could be served as volatile active components in ATEO which reflect the quality variation of ATEO in response to region difference. The results might be useful for the development of quality study of ATEO.

\section{Discussion}

The quality study of Chinese herbal medicine is a scientific problem and an industrial issue which hampers the development of Chinese medicine [38]. Region difference plays a key role in heterogeneous quality of Chinese herbal medicine and final drugs as the chemical composition and biological activity of the herbs vary with region $[3,39]$. However, current quality control approaches for Chinese herbal medicine are mostly focused on some targeted components which lack overall evaluation of the impact of region. Thus, the impact of region should be taken seriously and finding ways to explore the quality study of Chinese herbal medicine is of great importance.

ATR is one of the most important Chinese herbal medicines in treating neurological disorders. The primary active fraction of ATR is the essential oil. ATEO was reported to exert a neuroprotective effect in neurological disorders, including in neuroprotection on antioxidation, anti-inflammation and neurotrophic function [12-15]. The quality of ATEO varies widely due to region difference; however, little is known about how to study ATEO quality chemically and biologically in response to region difference. In this work, we identified volatile active components in ATEO from six major regions in China using chemical component analysis combined with biological activity evaluation to explore the quality study with region difference.

In the study, six major regions of ATR were involved, i.e. mountain areas in $\mathrm{AH}, \mathrm{HB}$ and $\mathrm{YN}$, valley area in $\mathrm{HN}$, hilly area in JX and hilly basin area in ZJ province. 


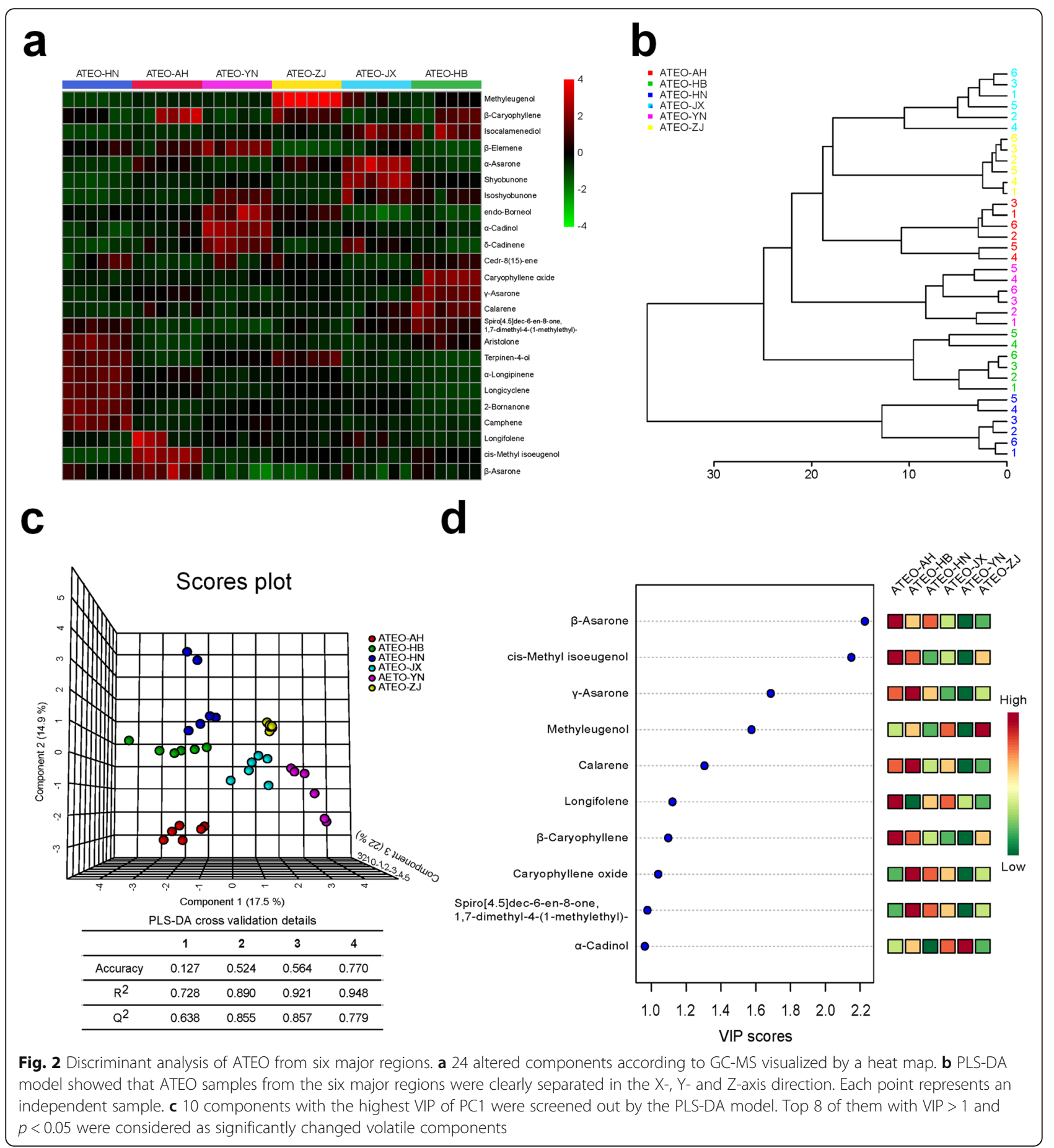

Some details of the geographical environment in six major regions were shown (Additional file 1). The variation in geographical environment resulted in diversity of secondary metabolites. Amongst all the secondary metabolites, $\beta$-asarone is considered as the major active component (45.88-69.97\% relative content), the content of which showed significant differences between groups (AH and $\mathrm{HB} ; \mathrm{AH}$ and JX; $\mathrm{AH}$ and $\mathrm{YN} ; \mathrm{AH}$ and ZJ; $\mathrm{HB}$ and $\mathrm{YN} ; \mathrm{HB}$ and ZJ; $\mathrm{HN}$ and JX; $\mathrm{HN}$ and $\mathrm{YN} ; \mathrm{HN}$ and $\mathrm{ZJ})$. It is interesting that ATEO-AH, ATEO-HB and ATEO-YN are from the mountain areas but ATEO from YN province in southwest China had lower content of $\beta$ asarone than that of samples in southeast China. The synthesis of $\beta$-asarone is promoted by phenylalanine ammonia lyase (PAL), one of the key enzymes in phenylpropanes metabolism pathway [40]. The activity of PAL 
Table 4 Significantly changed volatile components with their formula, compound type and VIP score identified through PLS-DA

\begin{tabular}{llll}
\hline Name of components & Formula & Component type & $\begin{array}{l}\text { PLS-DA } \\
\text { (VIP score) }\end{array}$ \\
\hline B-Asarone & $\mathrm{C} 12 \mathrm{H} 16 \mathrm{O} 3$ & Phenylpropanoids & 2.23 \\
cis-Methyl isoeugenol & $\mathrm{C} 11 \mathrm{H} 14 \mathrm{O} 2$ & Phenylpropanoids & 2.15 \\
Y-Asarone & $\mathrm{C} 12 \mathrm{H} 16 \mathrm{O} 3$ & Phenylpropanoids & 1.69 \\
Methyleugenol & $\mathrm{C} 11 \mathrm{H} 14 \mathrm{O} 2$ & Phenylpropanoids & 1.58 \\
Calarene & $\mathrm{C} 15 \mathrm{H} 24$ & Terpenoids & 1.31 \\
Longifolene & $\mathrm{C} 15 \mathrm{H} 24$ & Terpenoids & 1.12 \\
$\beta$-Caryophyllene & $\mathrm{C} 15 \mathrm{H} 24$ & Terpenoids & 1.10 \\
Caryophyllene oxide & $\mathrm{C} 15 \mathrm{H} 24 \mathrm{O}$ & Terpenoids & 1.04 \\
\hline
\end{tabular}

is affected by several exogenous factors, such as light, temperature, growth regulators, pathogen infection, injury, etc. [41]. It is reported that $\mathrm{YN}$ is the major mineral-producing province in China, and a lot of slag, waste gas and sewage are produced during the mining of minerals, causing soil heavy metal pollution. Heavy metal with high levels in soil causes toxic effects and decreases PAL activity [42], which may explain the low content of $\beta$-asarone in YN samples. From this point of view, the southeast regions might be suitable for ATR harvesting. Furthermore, much more effort is required to elucidate the reasons for the variation in chemical composition of ATEO samples.

The bioactivity assays studied in this work included regulation of anti-oxidative proteins (GPx1, SOD2 and UCP2), neurotrophic factors (NGF, BDNF and GDNF)
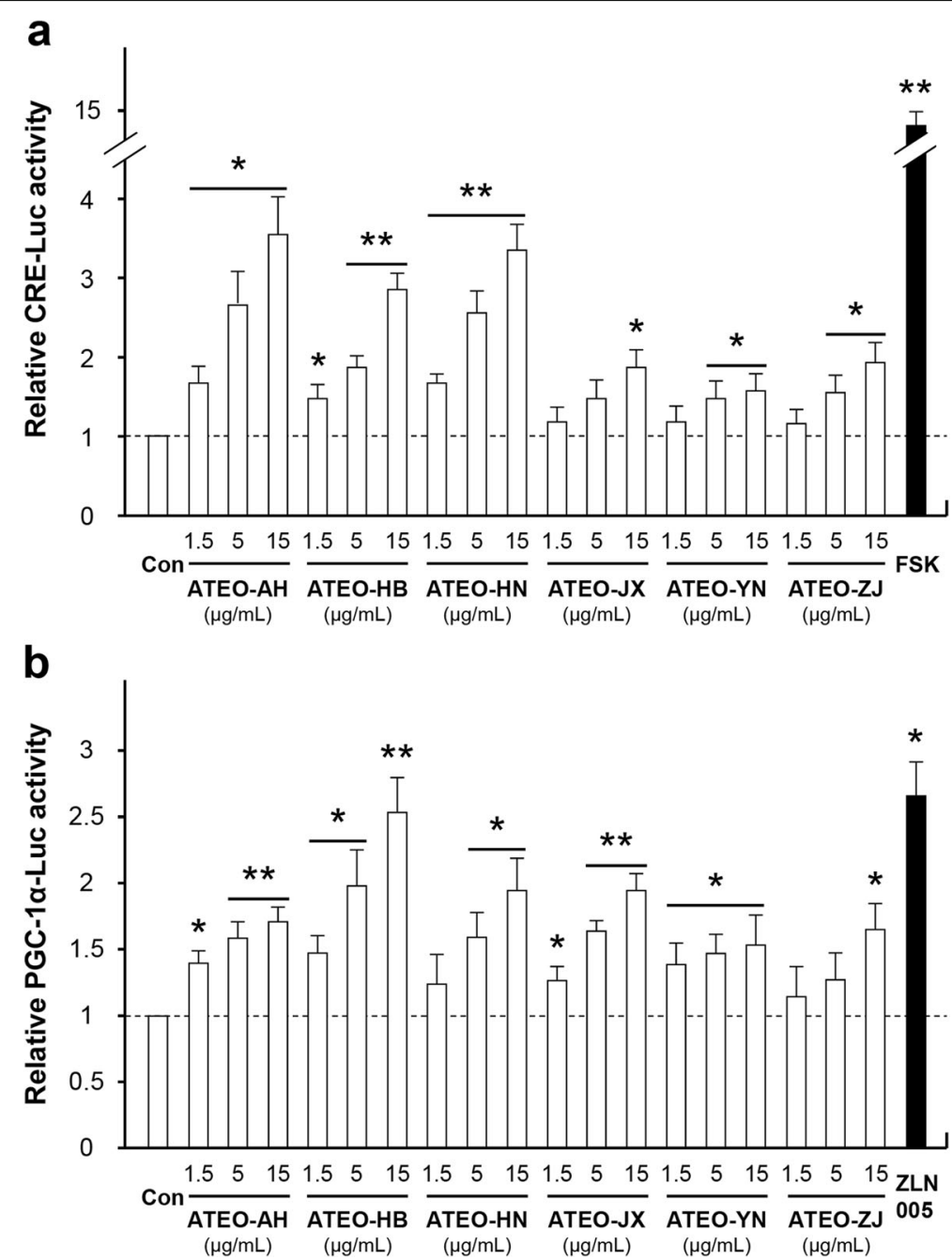

Fig. 3 ATEO stimulates transcriptional activities of CRE and PGC-1a in C6 cells. Cultured C6 cells were transfected with pCRE-LuC a or pPGC-1aLuc $\mathbf{b}$ and subsequently treated with ATEO $(1.5,5,15 \mu \mathrm{g} / \mathrm{mL})$ for $24 \mathrm{~h}$. Cells were collected to determine the luciferase activity. Forskolin (FSK, $10 \mu \mathrm{M})$ and ZLN005 $(2 \mu \mathrm{M})$ were used as positive control. Data are expressed as fold of control (untreated culture), and in mean \pm SEM, where $n=$ 3. ${ }^{*} p<0.05,{ }^{*} p<0.01$ compared with control 


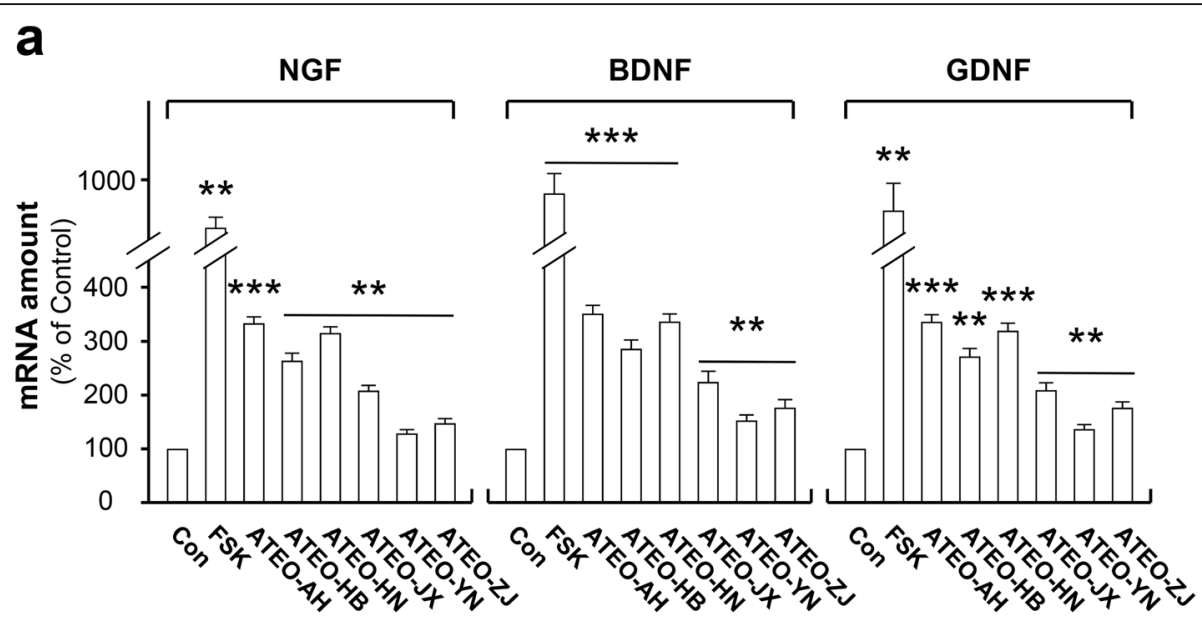

b

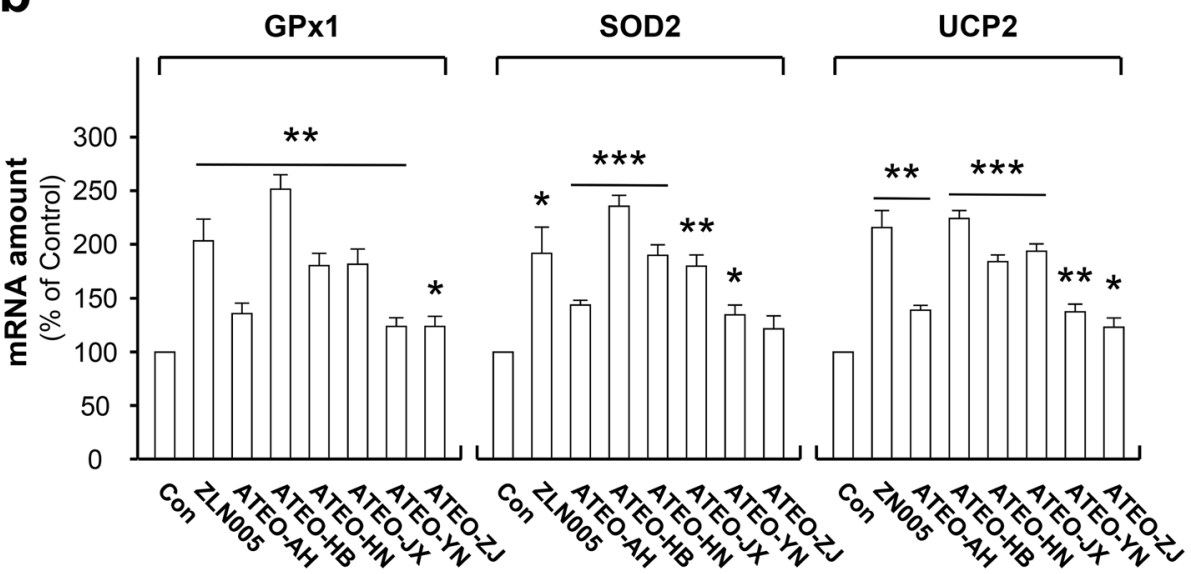

c

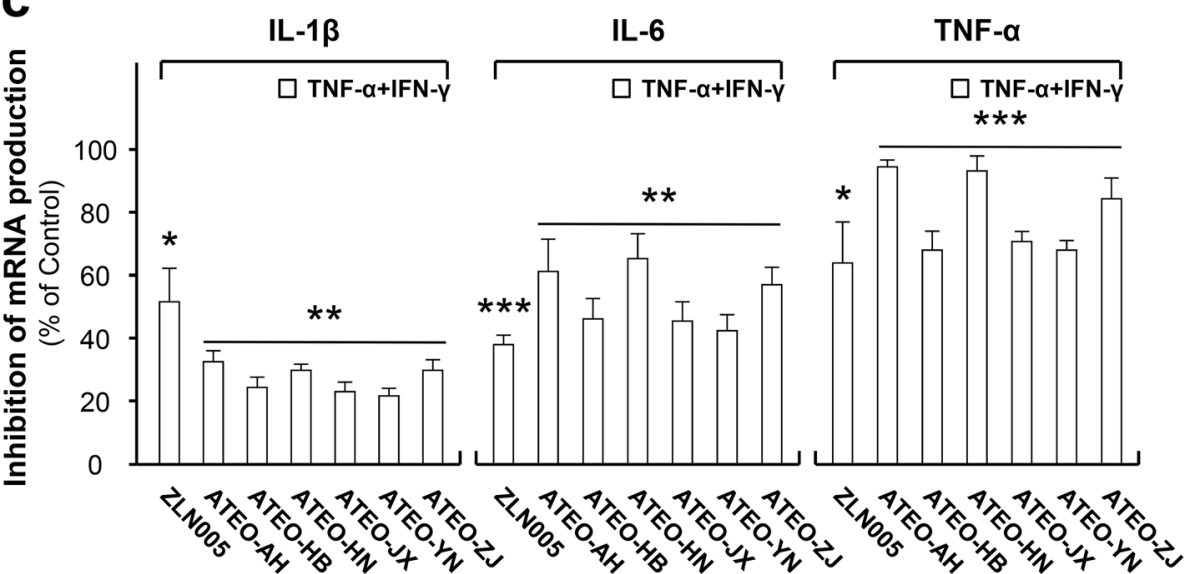

Fig. 4 ATEO regulates the expression of neuroprotective proteins in C6 cells. In neurotrophic (NGF, BDNF and GDNF, a) and anti-oxidation (GPx1, SOD2 and UCP2, b) activity, cultured C6 cells were treated with ATEO $(15 \mu \mathrm{g} / \mathrm{mL})$ for $48 \mathrm{~h}$. In anti-inflammation (IL-1 $\beta$, IL-6 and TNF-a, c) activity, cells were treated with ATEO $(15 \mu \mathrm{g} / \mathrm{mL})$ for $48 \mathrm{~h}$ before TNF- $\mathrm{a}$ and IFN- $\gamma(10+10 \mathrm{ng} / \mathrm{mL})$ co-treatment for another $24 \mathrm{~h}$. Cells were collected to determine the mRNA amount. Forskolin (FSK, $10 \mu \mathrm{M})$ and ZLN005 $(2 \mu \mathrm{M})$ were used as positive control. Data are expressed as percentage of control (untreated culture), and in mean \pm SEM, where $n=3 .{ }^{*} p<0.05,{ }^{* *} p<0.01,{ }^{* *} p<0.001$ compared with control

and pro-inflammatory cytokines (IL-1 $\beta$, IL-6 and TNF$\alpha)$. The up-regulation of anti-oxidative proteins (GPx1, SOD2 and UCP2) and inhibition of pro-inflammatory cytokines (IL-1 $\beta$, IL-6 and TNF- $\alpha$ ) could protect neurons against damage caused by injury, oxidative stress and inflammation, while the induction of neurotrophic factors could promote neuroregeneration [14, 43]. Our results indicated that ATEO exhibited anti- 


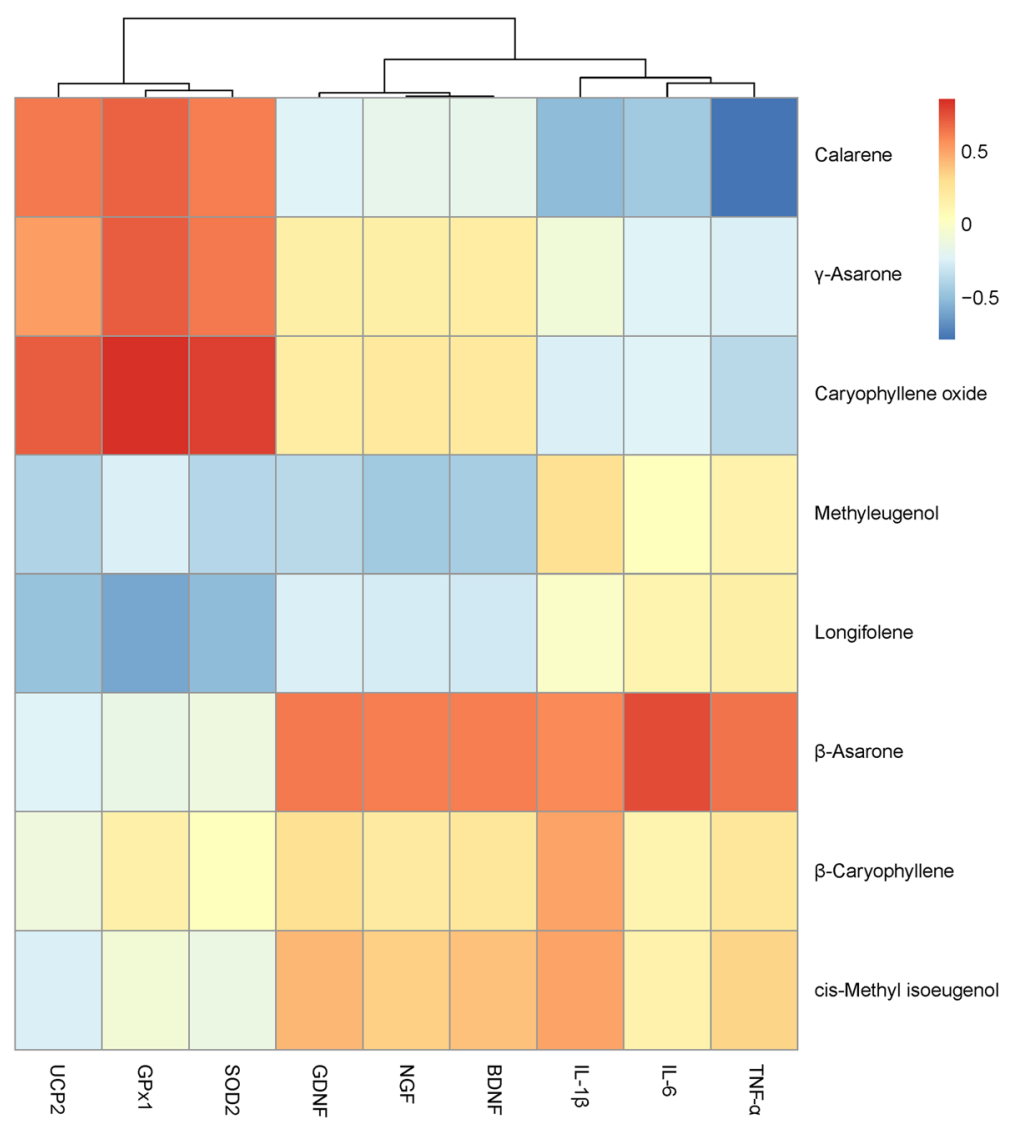

Fig. 5 Correlation analysis between GC/MS data and neuroprotective activity. Correlation analysis was performed for the activity data of neurotrophic factors (NGF, BDNF and GDNF), anti-oxidation (GPx1, SOD2 and UCP2) and anti-inflammation (IL-1 1 , IL-6 and TNF-a) and relative contents of significantly changed volatile components in ATEO using RStudio 1.1.463. The results were visualized on a heat map

oxidative, anti-inflammatory and neurotrophic effects which were supported by previous findings that ATEO protected $\mathrm{H}_{2} \mathrm{O}_{2}$-induced cell injury via CREB/PGC- $1 \alpha$ activation in PC12 cells and induced the expression of neurotrophic factors by protein kinase A (PKA) in cultured astrocytes $[15,44]$. The ATEO mediatedregulation of anti-oxidative effect was strongly correlated with the level of $\gamma$-asarone, while the regulation of antiinflammatory and neurotrophic activity by ATEO was closely related to the level of $\beta$-asarone. These activities of ATEO may be relevant to the traditional use of ATR: regaining consciousness, tranquilizing the mind, eliminating dampness, and invigorating the circulation of blood [45].

Based on these findings, 2 components ( $\beta$-asarone and $\gamma$-asarone) could be served as volatile active components of ATEO in response to region difference. $\beta$-Asarone (cis double bond) and $\alpha$-asarone (tran double bond) are sis-trans isomer in ATEO. They exert various

Table 5 Correlation coefficients between bioactivities and relative contents of significantly changed volatile components in ATEO

\begin{tabular}{llllllllll}
\hline Component & NGF & BDNF & GDNF & GPx1 & SOD2 & UCP2 & IL-1 & IL-6 & TNF- \\
\hline B-Asarone & 0.618 & 0.621 & 0.636 & -0.142 & -0.106 & -0.220 & 0.600 & 0.772 & 0.659 \\
cis-Methyl isoeugenol & 0.366 & 0.407 & 0.440 & -0.066 & -0.125 & -0.237 & 0.505 & 0.151 & 0.351 \\
Y-Asarone & 0.188 & 0.196 & 0.182 & 0.724 & 0.643 & 0.524 & -0.078 & -0.223 & -0.249 \\
Methyleugenol & -0.439 & -0.431 & -0.364 & -0.251 & -0.366 & -0.396 & 0.303 & 0.056 & 0.149 \\
Calarene & -0.154 & -0.167 & -0.227 & 0.709 & 0.632 & 0.647 & -0.506 & -0.435 & -0.776 \\
Longifolene & -0.253 & -0.276 & -0.249 & -0.595 & -0.503 & -0.466 & -0.002 & 0.136 & 0.175 \\
-Caryophyllene & 0.223 & 0.244 & 0.294 & 0.168 & 0.059 & -0.095 & 0.508 & 0.132 & 0.254 \\
Caryophyllene oxide & 0.233 & 0.224 & 0.191 & 0.862 & 0.810 & 0.722 & -0.246 & -0.226 & -0.364 \\
\hline
\end{tabular}


neuroprotective functions, such as anti-oxidation, promoting neuronal differentiation and neurotrophic factor expression $[13,15,46]$. It is worth noting that $\beta$-asarone showed greater effects on promoting neuronal differentiation and BDNF expression than that of $\alpha$-asarone, while these two asarones presented similar effect on antioxidation. These results indicate that double bond isomerization might play an important role in neurotrophic function, while the conversion of cis and trans isomers did not affect anti-oxidant property. Furthermore, much more effort is required to elucidate the structure and biological activities of asarones in ATEO.

\section{Conclusions}

In this study, the volatile active components of ATEO from six major regions in China were investigated by using an astrocyte-like cell line, C6 glioma cells. It was indicated that 8 components ( $\beta$-asarone, cis-methyl isoeugenol, $\gamma$-asarone, methyleugenol, terpenoids, calarene, longifolene, $\beta$-caryophyllene and caryophyllene oxide) in ATEO were significantly changed in response to region difference. And 2 components ( $\beta$-asarone and $\gamma$-asarone) showed strong correlation with the biological activities (anti-oxidative, anti-inflammatory and neurotrophic effects) which could be served as the volatile active components in quality study. These findings provide an insight into ATEO quality, which will be useful for the development of quality study of ATEO; further research should focus on validating the volatile active components of ATEO in cell and animal models.

\section{Supplementary information}

Supplementary information accompanies this paper at https://doi.org/10. 1186/s12906-020-03020-4.

Additional file 1. Details of geographical environment of six major regions.

Additional file 2. Identification of components in ATEO.

Additional file 3. Effect of ATEO on the growth of cultured C6 cells.

Additional file 4. Effect of TNF- $a$ and IFN- $-y$ on the pro-inflammatory cytokine mRNA expression of cultured C 6 cells.

Additional file 5. The original $\mathrm{rPCR}$ data of ATEO bioactivity.

\section{Abbreviations}

ATR: Acori Tatarinowii Rhizome; ATEO: Acori Tatarinowii Rhizome essential oil; GC-MS: Gas Chromatography-Mass Spectrometer; DAL: Drug Administration Law; GAP: Good Agricultural Practices; AH: Anhui; HB: Hubei; HN: Hunan; JX: Jiangxi; YN: Yunnan; ZJ: Zhejiang; PLS-DA: partial least-squares discriminant analysis; ANOVA: Analysis of Variance; El: Electron impact;

ATCC: American Type Culture Collection; DMEM: Dulbecco's modified Eagle's medium; FBS: Fetal bovine serum; FSK: Forskolin; TNF-a: Tumor necrosis factor-a; IFN- $\gamma$ : Interferon- $\gamma$; CRE: CAMP response element; PGC1a: Peroxisome proliferator-activated receptor- $\gamma$ coactivator-1a; MCA: Multicriteria assessment; VIP: Variable importance in projection; FDR: False discovery rate; IL-1 $\beta$ : Interleukin-1 $\beta$; IL-6: Interleukin-6; CREB: CAMP-response element binding protein; GPx1: Glutathione peroxidase 1; SOD2: Superoxide Dismutase 2; UCP2: Uncoupling protein2; NGF: Nerve growth factor;
BDNF: Brain-derived neurotrophic factor; GDNF: Glial cell-derived neurotrophic factor; PAL: Phenylalanine ammonia lyase; PKA: Protein kinase A

\section{Acknowledgements}

Not applicable.

\section{Authors' contributions}

$L Y$ and MW designed research; LY conducted research; $Y Q$ and PS collected data; $Z \mathrm{~L}$ and $\mathrm{LX}$ analyzed data; $\mathrm{LY}$ wrote the paper; $\mathrm{LY}$ and MW revised the manuscript. All authors read and approved the final manuscript.

\section{Funding}

This research was funded by National Natural Science Foundation of China (grant number: 81603374,81803758 ) and the program of Jiangsu Key laboratory for the Research and Utilization of Plant Resources (grant number: JSPKLB201607, JSPKLB201818). The funders played no role in the design of this study, and collection, analysis and interpretation of data and writing the manuscript.

\section{Availability of data and materials}

All data generated or analyzed during this study are included in this published article and its supplementary information files.

Ethics approval and consent to participate

Not applicable.

\section{Consent for publication}

Not applicable.

\section{Competing interests}

The authors declare that they have no competing interests.

\section{Author details}

${ }^{1}$ Institute of Botany, Jiangsu Province and Chinese Academy of Sciences, Nanjing 210014, China. ${ }^{2}$ Jiangsu Key Laboratory for the Research and Utilization of Plant Resources, Nanjing 210014, China. ${ }^{3}$ The Jiangsu Provincial Platform for Conservation and Utilization of Agricultural Gerplasm, Nanjing 210014, China. ${ }^{4}$ North Information Control Research Academy Group Co., Ltd., Nanjing 211153, China. ${ }^{5}$ State Key Laboratory of Environmental Chemistry and Ecotoxicology, Research Center for Eco-Environmental Science, Chinese Academy Sciences, Beijing 100085, China.

Received: 11 March 2020 Accepted: 8 July 2020

Published online: 17 August 2020

References

1. Zhang J, Wider B, Shang H, Li X, Ernst E. Quality of herbal medicines: challenges and solutions. Complement Ther Med. 2012;20:100-6.

2. Liu SH, Chuang WC, Lam W, Jiang Z, Cheng YC. Safety surveillance of traditional Chinese medicine: current and future. Drug Saf. 2015:38:117-28.

3. Sendker J, Sheridan H. Composition and quality control of herbal medicines. Toxicol Herbal Products. 2017. https://doi.org/10.1007/978-3-319-43806-1_3.

4. Chen A, Sun L, Yuan H, Wu A, Lu J, Ma S. A holistic strategy for quality and safety control of traditional Chinese medicines by the "iVarious" standard system. J Pharm Anal. 2017;7:271-9.

5. Fan TP, Deal G, Koo HL, Rees D, Sun H, Chen S, et al. Future development of global regulations of Chinese herbal products. J Ethnopharmacol. 2012;140: 568-86.

6. Wiesner J, Knöss W. Future visions for traditional and herbal medicinal products-a global practice for evaluation and regulation? J Ethnopharmacol. 2014:158:516-8

7. Yan L, Wei M, Gong AG, Song P, Lou J, Bi CW, et al. A modified Chinese herbal decoction (Kai-Xin-san) promotes NGF-induced neuronal differentiation in PC12 cells via up-regulating Trk a signaling. Front Cell Dev Biol. 2017;5:118.

8. Liu L, Mao D, Chi K, Li X, Bo T, Guo J, et al. Effects of Rhizoma Acori Tatarinowii extracts on gamma-aminobutyric acid type a receptor alpha 1 subunit brain expression during development in a recurrent seizure rat model. Neural Regen Res. 2011;6:412-7. 
9. Mao J, Huang S, Liu S, Feng XL, Yu M, Liu J, et al. A herbal medicine for Alzheimer's disease and its active constituents promote neural progenitor proliferation. Aging Cell. 2015;14:784-96.

10. Xu QQ, Shan CS, Wang Y, Shi YH, Zhang QH, Zheng GQ. Chinese herbal medicine for vascular dementia: a systematic review and meta-analysis of high-quality randomized controlled trials. J Alzheimers Dis. 2018;62:429-56.

11. National Pharmacopoeia Committee. Pharmacopoeia of People's Republic of China. Beijing: China Medical Science and Technology Press; 2015. p. 912

12. Han P, Han T, Peng W, Wang XR. Antidepressant-like effects of essential oil and asarone, a major essential oil component from the rhizome of Acorus tatarinowii. Pharm Biol. 2013;51:589-94.

13. Lam KYC, Yao P, Wang H, Duan R, Dong TTX, Tsim KWK. Asarone from Acori Tatarinowii Rhizome prevents oxidative stress-induced cell injury in cultured astrocytes: a signaling triggered by Akt activation. PLoS One. 2017;12: e0179077.

14. Song Z, Yin F, Xiang B, Lan B, Cheng S. Systems pharmacological approach to investigate the mechanism of Acori Tatarinowii Rhizoma for Alzheimer's disease. Evid Based Complement Alternat Med. 2018;5194016:20. https://doi. org/10.1155/2018/5194016.

15. Lam KYC, Wu QY, Hu WH, Yao P, Wang HY, Dong TTX, et al. Asarones from Acori Tatarinowii Rhizoma stimulate expression and secretion of neurotrophic factors in cultured astrocytes. Neurosci Lett. 2019;707:134308.

16. Chen XL, Yuan DJ, Wu XR, Wu QD. Comparative study on quality of volatile oil of Acori Tatarinowii Rhizoma from two habitats. Zhong Yao Cai. 2015;38: 770-3.

17. Guo DA. Quality marker concept inspires the quality research of traditional Chinese medicine. Chin Herbal Med. 2017;9:1-2.

18. Zhang T, Bai G, Han Y, Xu J, Gong S, Li Y, et al. The method of quality marker research and quality evaluation of traditional Chinese medicine based on drug properties and effect characteristics. Phytomedicine. 2018;44 204-11.

19. Chao J, Dai Y, Cheng HY, Lam W, Cheng YC, Li K, et al. Improving the concentrations of the active components in the herbal tea ingredient, Uraria crinita: The effect of post-harvest oven-drying processing. Sci Rep. 2017;7:38763.

20. Nijland PG, Witte ME, van het Hof B, van der Pol S, Bauer J, Lassmann H, et al. Astroglial PGC-1alpha increases mitochondrial antioxidant capacity and suppresses inflammation: implications for multiple sclerosis. Acta Neuropathol Commun. 2014:2:170.

21. Verkhratsky A. Astroglial calcium signaling in aging and Alzheimer's disease. Cold Spring Harb Perspect Biol. 2019;11:a035188.

22. Kaddour H, Hamdi Y, Amri F, Bahdoudi S, Bouannee I, Leprince J, et al. Antioxidant and anti-apoptotic activity of octadecaneuropeptide against 6OHDA toxicity in cultured rat astrocytes. J Mol Neurosci. 2019;69:1-16.

23. Galland F, Seady M, Taday J, Smaili SS, Gonçalves CA, Leite MC. Astrocyte culture models: molecular and function characterization of primary culture immortalized astrocytes and C6 glioma cells. Neurochem Int. 2019;131: 104538

24. Ma SS, Zhang BY, Chen L, Zhang XJ, Ren DB, Yi LC. Discrimination of Acori Tatarinowii Rhizoma from two habitats based on GC-MS fingerprinting and LASSO-PLS-DA. J Cent South Univ. 2018;25(5):1063-75.

25. Do H, Pyo S, Sohn EH. Suppression of iNOS expression by fucoidan is mediated by regulation of p38 MAPK, JAK/STAT, AP-1 and IRF-1, and depends on up-regulation of scavenger receptor B1 expression in TNFalpha- and IFN-gamma-stimulated C6 glioma cells. J Nutr Biochem. 2010;21: $671-9$.

26. Gong AGW, Wang HY, Dong TTX, Tsim KWK, Zheng YZ. Danggui Buxue tang, a simple Chinese formula containing Astragali Radix and Angelicae Sinensis Radix, stimulates the expressions of neurotrophic factors in cultured SH-SY5Y cells. Chin Med. 2017;12:24

27. Chong J, Wishart DS, Xia J. Using MetaboAnalyst 4.0 for comprehensive and integrative metabolomics data analysis. Curr Protoc Bioinformatics. 2019;68: e86.

28. Triba MN, Le Moyec L, Amathieu R, Goossens C, Bouchemal N, Nahon P, et al. PLS/OPLS models in metabolomics: the impact of permutation of dataset rows on the K-fold cross-validation quality parameters. Mol BioSyst. 2015;11:13-9.

29. An Y, Cai H, Yang Y, Zhang Y, Liu S, Wu X, et al. Identification of ENTPD8 and cytidine in pancreatic cancer by metabolomic and transcriptomic conjoint analysis. Cancer Sci. 2018;109:2811-21.
30. Liu Y, Miao Z, Guan W, Sun B. Analysis of organic volatile flavor compounds in fermented stinky tofu using SPME with different fiber coatings. Molecules. 2012;17:3708-22.

31. Satyal P, Paudel P, Poudel A, Dosoky NS, Moriarity DM, Vogler B, et al. Chemical compositions, phytotoxicity, and biological activities of Acorus calamus essential oils from Nepal. Nat Prod Commun. 2013;8:1179-81.

32. Dong H, Zhang Q, Li L, Liu J, Shen L, Li H, et al. Antioxidant activity and chemical compositions of essential oil and ethanol extract of Chuanminshen violaceum. Ind Crop Prod. 2015;76:290-7.

33. Dave PC, Vogler B, Setzer WN. Chemical compositions of the leaf essential oils of Aralia spinosa from three habitats in northern Alabama. Am J Plant Sci. 2011;2:507-10.

34. Jodeiri Farshbaf M, Ghaedi K, Megraw TL, Curtiss J, Shirani Faradonbeh M, Vaziri $P$, et al. Does PGC1a/FNDC5/BDNF elicit the beneficial effects of exercise on neurodegenerative disorders? NeuroMolecular Med. 2016;18:115

35. Kang $H$, Khang $R$, Ham S, Jeong GR, Kim H, Jo M, et al. Activation of the ATF2/CREB-PGC-1a pathway by metformin leads to dopaminergic neuroprotection. Oncotarget. 2017;8:48603-18.

36. Li C, Chen T, Zhou H, Feng Y, Hoi MPM, Ma D, et al. BHDPC is a novel neuroprotectant that provides anti-neuroinflammatory and neuroprotective effects by inactivating NF-KB and activating PKA/CREB. Front Pharmacol. 2018;9:614

37. de Bot CM, Moed H, Bindels PJ, van Wijk RG, Berger MY, de Groot $H$, et al. Exhaled nitric oxide measures allergy not symptoms in children with allergic rhinitis in primary care: a prospective cross-sectional and longitudinal cohort study. Prim Care Respir J. 2013;22:44-50.

38. Zhou Y, Zhang D, Li H, Zhang H, Fang J, Ma Y, et al. The scientific basis and advantage of human experiential assessment in the quality control of Chinese herbal medicines exampling as Schisandrae Chinensis Fructus. Sci Rep. 2018;8:5695.

39. Yang J, Duan JA, Li GL, Zhu ZH, Zhu TL, Qian DW, et al. Determination of lignans in schisandrae sphenantherae fructus from different regions. Zhongguo Zhong Yao Za Zhi. 2014;39:4647-52.

40. Shadle GL, Wesley SV, Korth KL, Chen F, Lamb C, Dixon RA. Phenylpropanoid compounds and disease resistance in transgenic tobacco with altered expression of L-phenylalanine ammonia-lyase. Phytochemistry. 2003;64:15-161.

41. Roubelakis-Angelakis K, Kliewer WM. Effects of exogenous factors on phenylalanine ammonia-lyase activity and accumulation of anthocyanins and total phenolics in grape berries. Am J Enol Viticult. 1986;37:275-80.

42. Dai LP, Xiong ZT, Huang Y, Li MJ. Cadmium-induced changes in pigments, total phenolics, and phenylalanine ammonia-lyase activity in fronds of Azolla imbricata. Environ Toxicol. 2006:21:505-12.

43. Wagenaar N, de Theije CGM, de Vries LS, Groenendaal F, Benders MJNL, Nijboer CHA. Promoting neuroregeneration after perinatal arterial ischemic stroke: Neurotrophic factors and mesenchymal stem cells. Pediatr Res. 2018; 83:372-84.

44. Yan L, Mahady G, Qian Y, Song P, Jian T, Ding X, et al. The essential oil from Acori Tatarinowii Rhizome (the dried rhizome of Acorus tatarinowii Schott) prevents hydrogen peroxide-induced cell injury in PC12 cells: a signaling triggered by CREB/PGC-1a activation. Evid Based Complement Alternat Med. 2020;4845028:12. https://doi.org/10.1155/2020/4845028.

45. Yan L, Hu Q, Mak MS, Lou J, Xu SL, Bi CW, et al. A Chinese herbal decoction, reformulated from Kai-Xin-san, relieves the depression-like symptoms in stressed rats and induces neurogenesis in cultured neurons. Sci Rep. 2016;6: 30014.

46. Lam KY, Chen J, Lam CT, Wu Q, Yao P, Dong TT, et al. Asarone from Acori Tatarinowii Rhizoma potentiates the nerve growth factor-induced neuronal differentiation in cultured PC12 cells: a signaling mediated by protein kinase a. PLoS One. 2016;11:e0163337.

\section{Publisher's Note}

Springer Nature remains neutral with regard to jurisdictional claims in published maps and institutional affiliations. 